\title{
Analysis of clinical and pathological factors in patients undergoing surgery for rectal cancer: a single-centre experience with 692 patients in China
}

\section{Liping Xu}

Nanjing medical University, First Affiliated Hospital https://orcid.org/0000-0001-6977-3245

Chi Zhang

Nanjing Medical University, First Affiliated Hospital

\section{Zhaoyue Zhang}

Nanjing Medical Universtiy, First Affiliated Hospital

\section{Xinyu Tang}

Nanjing Medical University, First Affiliated Hospital

\section{Qin Qin}

Nanjing Medical Universtiy, Affiliated Hospital

Xinchen Sun ( $\square$ sunxinchen2012@163.com )

\section{Research}

Keywords: Rectal cancer, Pathological results, Pathologic T stage, Lymph node metastasis (LNM)

Posted Date: March 24th, 2020

DOI: https://doi.org/10.21203/rs.3.rs-18628/v1

License: (a) (1) This work is licensed under a Creative Commons Attribution 4.0 International License. Read Full License 


\section{Abstract}

Background: The management of rectal carcinoma has substantially evolved over the past two decades, so as AJCC staging and NCCN guidelines. The inherent relationships of pathologic factors warrant further study. The present study aimed to assess the associations of clinical and pathological factors in rectal cancer patients undergoing radical surgery.

Methods: From October 2015 to February 2019, all rectal cancer patients treated with radical surgery without neoadjuvant therapy were identified. The analysis was performed with data obtained from the prospectively collected database. Predictive factors for lymph node metastasis were analysed.

Results: In total, 692 patients with a median age of 61.64 years (range: 22-89) were included. There was no significant difference in onset age between male and female patients $(61.75 \pm 11.10$ vs $61.43 \pm 11.92$, $\mathrm{P}=0.723)$.

Tumour location ( $P=0.004)$, perineural invasion $(P N I)(P=0.000)$, lymphovascular invasion $(L V I)(P=0.000)$, tumour deposit (TD) $(P=0.000)$, and differentiation grade $(P=0.000)$ were significantly related to pathologic $T$ stage in univariate analysis, while sex was not $(p=0.192)$.

Compared to patients with $\mathrm{T} 1$ disease, there was a significantly higher proportion of positive LVI in patients with stage $T 3$ disease $(P=0.011, O R=3.404,95 \% \mathrm{Cl}: 1.319-8.787)$ but not in those with T2 $(P=0.686$, $\mathrm{OR}=0.804,95 \% \mathrm{Cl}: 0.280-2.310)$ and T4 ( $\mathrm{P}=0.063, \mathrm{OR}=3.200,95 \% \mathrm{Cl}: 0.941-10.886)$ disease. Compared to patients with $\mathrm{T} 2$ disease, there was a significantly higher proportion of perineural invasion in patients with stage T3 ( $P=0.000, O R=6.2376,95 \%$ Cl: 3.371-11.685) but not T4 ( $P=0.172, O R=2.309,95 \%$ Cl: 0.694-7.676) disease. Compared to patients with $\mathrm{T} 1$ disease, a significantly higher proportion of TDs occurred in patients with stage T3 ( $P=0.013$, OR=6.106, 95\% Cl: 1.455-25.631) and stage T4 ( $P=0.019, \mathrm{OR}=7.146,95 \%$ Cl: 1.378$37.044)$ but not stage T2 ( $P=0.435, \mathrm{OR}=0.503,95 \% \mathrm{Cl}: 0.089-2.824)$ disease. The overall incidence of lymph node metastasis was $44.9 \%$ (19.6\% for T1, $23.6 \%$ for $\mathrm{T} 2,56.7 \%$ for T3, and $67.8 \%$ for T4). Patient age, sex, and tumour location did not significantly affect lymph node metastasis (LNM). The presence of LVI $(\mathrm{OR}=3.882,95 \% \mathrm{Cl}=2.338-6.440, \mathrm{P}=0.000), \mathrm{TD}(\mathrm{OR}=27.645,95 \% \mathrm{Cl}=9.805-77.947, \mathrm{P}=0.000)$, higher $\mathrm{T}$ stage $(\mathrm{OR}=1.969,95 \% \mathrm{Cl}=1.471-2.635, \mathrm{P}=0.000)$, and poorly differentiated histology $(\mathrm{OR}=2.255,95 \% \mathrm{Cl}=1.544-$ $3.293, P=0.000$ ) were associated with a higher incidence of $L N M$ on multivariate analysis. Perineural invasion $(P=0.000)$ significantly affected $L N M$ in univariate but not multivariate analysis $(O R=1.213,95 \%$ $\mathrm{Cl}=0.734-2.003, \mathrm{P}=0.452)$.

Conclusion: There was no significant difference between male and female patients in onset age. Tumour location, $\mathrm{PNI}, \mathrm{LVI}, \mathrm{TD}$, and differentiation grade were significantly related to pathologic $\mathrm{T}$ stage. Patients with the presence of LVI and TD, higher T stage, and poorly differentiated histology have a significantly higher chance of LNM.

\section{Background}


The management of rectal carcinoma has substantially evolved over the past two decades. Radical resection is the preferred treatment for early rectal cancer, and neoadjuvant radiochemotherapy (nRCT) followed by total mesorectal excision (TME) has been the standard recommended therapy for locally advanced rectal carcinoma (LARC)[1-7].

Surgical resection remains the most effective therapy for rectal cancers. Pathologic findings in surgical resection specimens are the best predictor of prognosis. The main postoperative pathological information includes tumour differentiation grade, macroscopic type, lymphovascular invasion (LVI), perineural invasion (PNI), tumour deposit (TD), primary tumour stage, and lymph node stage. AJCC staging and NCCN guidelines have been updated in recent decades. For example, the classification of tumour nodules as TDs versus LNs has been debated in the past. Since the AJCC 7th (2010) edition, the new nodal subclassification category N1c is used if there are TDs but no concurrent positive LNs[8]. The percentage of LN metastasis has also changed in the new classifications. Therefore, the inherent relationships of these pathologic factors warrant further study. The present study aimed to explore the correlations of clinical and pathological factors in patients undergoing surgery for rectal cancer.

\section{Materials And Methods}

\section{Patients}

We enrolled 1061 patients with primary rectal cancer who had undergone radical resection at the First Affiliated Hospital of Nanjing Medical University between October 2015 and February 2019. The inclusion criteria for the study were as follows: (1) preoperative pathological diagnosis of rectal cancer diagnosed by endoscopy-guided biopsy; (2) inferior tumour margin located within $15 \mathrm{~cm}$ of the anal verge; (3) detailed postoperative pathological reports including histological differentiation grade, depth of tumour invasion, macroscopic type, number of LNs examined, LN metastasis, TD, lymphovascular invasion (LVI), and perineural invasion (PNI); (4) no evidence of distant metastasis; and (5) no history of malignancy other than nonmelanoma skin cancer. Patients were excluded if they met the following criteria: (1) received previous neoadjuvant chemoradiotherapy (CRT) or chemotherapy before surgical resection; (2) tumour located > $15 \mathrm{~cm}$ from the anal verge; and (3) fewer than $10 \mathrm{LNs}$ removed. Among the 1061 patients, 219 received neoadjuvant CRT or chemotherapy; 116 had tumours located $>15 \mathrm{~cm}$ from the anal verge; and 34 had inadequate LN detection; all of these patients were excluded from the study. The remaining 692 patients were analysed (Fig. 1). This retrospective study was approved by the Institutional Research Ethics Committee of the First Affiliated Hospital of Nanjing Medical University.

\section{Surgery and histopathological examinations}

The 692 patients underwent curative TME. Samples were obtained from opposite side of the resected specimens and fixed in formalin for $24 \mathrm{~h}$ after surgery. The specimens were then sliced transversely at increments of $5 \mathrm{~mm}$. The slices were embedded in paraffin, sectioned, and examined histologically after haematoxylin and eosin (HE) staining. The results were evaluated by experienced pathologists. The histological grade, presence of LN metastasis, LNI and PNI were all evaluated. 


\section{Statistical analysis}

The study was designed to identify clinicopathologic variables that could be associated with the pathological $\mathrm{T}$ and $\mathrm{N}$ stages. Categorical variables such as patient demographics (such as sex) and tumour characteristics (such as tumour location, differentiation grade, PNI, LVI, TD, and pathologic $\mathrm{T}$ and $\mathrm{N}$ staging) were compared with chi-square tests, while for continuous variables such as patient age, Student's t tests and analysis of variance (ANOVA) were used. Multiple covariate analysis was performed using the stepwise regression hazards regression model. The hazard ratio (HR) and $P$ value with the $95 \%$ confidence interval $(\mathrm{Cl})$ were calculated for the variable groups. All $P$ values were 2-tailed, and $P$ values less than 0.05 were considered statistically significant. Statistical analyses were performed with SPSS version 19.0 (SPSS, Chicago, IL).

\section{Results}

\section{Patient Demographics And Clinicopathologic Data}

The patient characteristics are shown in Table 1. There were 245 females (35.4\%) and 447 males (64.6\%), with a mean age of $61.64 \pm 11.39$ (range: $22-89$ ) years. The average age at the onset of rectal cancer was $61.43 \pm 11.92$ years for female patients and $61.75 \pm 11.10$ years for male patients. There was no significant difference in onset age between female and male patients $(F=0.126, P=0.723)$. In total, $98(14.2 \%)$ patients had upper-rectal cancer $(10-15 \mathrm{~cm}), 346(50 \%)$ patients had mid-rectal cancer $(5-10 \mathrm{~cm}$ from the anal verge), and 248 (35.8\%) patients had lower rectal cancer (less than $5 \mathrm{~cm}$ from the anal verge) (Table 1). 
Table 1

Characteristics of the patients $(n=692)$

\section{Characteristics}

Sex, n (\%)

Female

Male

Age, median \pm SD (years)

Tumor location $(\mathrm{cm})$

$\leq 5 \mathrm{~cm}$

5-10 cm

$>10 \mathrm{~cm}, \leq 15 \mathrm{~cm}$

Pathology, n (\%)

Common adenocarcinoma

Mucinous adenocarcinoma

Signet ring cell carcinoma

Neuroendocrine carcinoma

Others

Tumor differentiation grade, $\mathrm{n}(\%)$

Moderate-high

Low

TD, n (\%)

Negative

Positive

LVI, n (\%)

Negative

Positive

PNI, n (\%)

Negative

Positive

\section{Number of patients (\%)}

Age, median, years

245 (35.4\%)

$61.43 \pm 11.92$

447 (64.6\%)

$61.75 \pm 11.10$

$61.64 \pm 11.39$
$248(35.8 \%)$

$346(50 \%)$

98(14.2\%)

$639(92.3 \%)$

$34(4.9 \%)$

$7(1.0 \%)$

$4(0.6 \%)$

$8(0.8 \%)$

245(35.4\%)

597 (86.3\%)

$95(13.7 \%)$

$552(79.8 \%)$

$140(20.2 \%)$

$558(80.6 \%)$

134(19.4\%)

$\mathrm{TD}=$ tumour deposit, $\mathrm{LVI}=$ lymphovascular invasion, $\mathrm{PNI}=$ perineural invasion 


\begin{tabular}{|ll|}
\hline Characteristics & Number of patients (\%) \\
\hline Pathologic T stage, $\mathrm{n}(\%)$ & \\
\hline T1 & $199(7.4 \%)$ \\
\hline T2 & $411(59.4 \%)$ \\
\hline T3 & $31(4.5 \%)$ \\
\hline T4 & \\
\hline Pathological N stage, $n(\%)$ & $381(55.1 \%)$ \\
\hline N0 & $189(27.3 \%)$ \\
\hline N1 & $122(17.6 \%)$ \\
\hline N2 & \\
\hline TD = tumour deposit, LVI = lymphovascular invasion, PNI = perineural invasion. \\
\hline
\end{tabular}

Regarding histological type, 639 (92.3\%) tumours were common adenocarcinomas, 34 (4.9\%) were mucinous adenocarcinomas, $7(1.0 \%)$ were signet ring cell carcinomas, and $4(0.6 \%)$ were neuroendocrine carcinomas. The histologic diagnoses were moderately differentiated adenocarcinoma in 447 (64.6\%) patients and poorly differentiated adenocarcinoma in 245 (35.4\%) patients (Table 1).

A total of $86.3 \%$ (597/692) of patients were TD negative, and 13.7\% (95/692) were positive. A total of $79.8 \%$ $(552 / 692)$ of the patients were LVI negative, and $20.2 \%$ (140/692) were LVI positive. PNI was found in $19.4 \%$ $(134 / 692)$ of the patients, while PNI was absent in $80.6 \%$ (558/692). With regard to the pathological T and $N$ stages, 51 (7.4\%), 199 (28.8\%), 411 (59.4\%), 31 (4.5\%) patients had T1, T2, T3 and T4 disease, while 381 (55.1\%), 189 (27.3\%), and 122 (17.6\%) had N0, N1 and N2 disease.

\section{Association Between Pathological T Stage And N Stage}

Table 2 and Figs. 2 and 3 show the associations between each pathological T1-4 stage and N0-3 stage. For pathologic stage $\mathrm{T} 1$, the percentages of N0, N1 and N2 were $80.4 \%, 15.7 \%$ and $3.9 \%$, respectively. For pathologic stage $\mathrm{T} 2$, the percentages of $\mathrm{N} 0, \mathrm{~N} 1$ and $\mathrm{N} 2$ were $76.4 \%, 17.1 \%$ and $6.5 \%$, respectively. For pathologic stage $\mathrm{T} 3$, the percentages of N0, N1 and N2 were $43.3 \%, 33.3 \%$ and $23.4 \%$, respectively. For pathologic stage $\mathrm{T} 4$, the percentages of $\mathrm{N} 0, \mathrm{~N} 1$ and $\mathrm{N} 2$ were $32.3 \%, 32.3$ and $35.5 \%$, respectively (Table 2). Figure 2 shows that an increased T stage was associated with an increased percentage of N1 and N2. Goodman-Kruskal gamma statistic analysis confirmed this result (gamma $=0.579, \mathrm{P}=0.000$ ). 
Table 2

Distribution of T stage and $\mathrm{N}$ stages in 692 patients with rectal cancer.

\begin{tabular}{|llll|}
\hline T stage & N stage & & \\
\cline { 2 - 4 } & N0 & N1 & N2 \\
\hline T1 & $80.4 \%(41 / 51)$ & $15.7 \%(8 / 51)$ & $3.9 \%(2 / 51)$ \\
\hline T2 & $76.4 \%(152 / 199)$ & $17.1 \%(34 / 199)$ & $6.5 \%(13 / 199)$ \\
\hline T3 & $43.3 \%(178 / 411)$ & $33.3 \%(137 / 411)$ & $23.4 \%(96 / 411)$ \\
\hline T4 & $32.3 \%(10 / 31)$ & $32.3 \%(10 / 31)$ & $35.5 \%(11 / 31)$ \\
\hline
\end{tabular}

Figure 3 shows the average number of metastatic LNs for each pathologic T stage. The mean numbers of metastatic LNs in patients with $\mathrm{T} 1, \mathrm{~T} 2, \mathrm{~T} 3$, and T4 disease were $0.59 \pm 2.22,0.62 \pm 1.391,2.41 \pm 3.796$, and $3.26 \pm 4.719$, respectively. Multiple comparisons by analysis of variance (ANOVA) showed that there was no significant difference in the average number of metastatic $L N$ s between $T 1$ and $T 2(P=0.953)$ or $T 3$ and T4 $(P=0.160)$. However, significant differences were observed between T1 and T3 $(P=0.000), T 1$ and T4 $(P=$ $0.000)$, $T 2$ and T3 $(P=0.000)$, and T2 and T4 $(P=0.000)$.

\section{Clinicopathologic variables that correlate with the T stage}

We analysed the clinicopathological factors that could be correlated with the pathological T stage, as shown in Table 3. On univariate analysis, tumour location $(P=0.004)$, PNI $(P=0.000)$, LVI $(P=0.000), T D(P=$ $0.000)$, and differentiation grade $(P=0.000)$ were significantly correlated with the pathological $T$ stage, but sex was not $(p=0.192)$. 
Table 3

Associations between clinicopathological variables and pathological T stage

\begin{tabular}{|c|c|c|c|c|c|c|c|}
\hline & & & $x^{2}$ & $\mathbf{P}$ & Exp & $95 \% \mathrm{Cl}$ & $\mathbf{P}$ \\
\hline & \multicolumn{7}{|l|}{$\operatorname{PNI}(\mathrm{n})$} \\
\hline & Negative & positive & 58.728 & 0.000 & & & \\
\hline T1 & 51 & 0 & & & - & & \\
\hline T2 & 187 & 12 & & & 1 & & \\
\hline T3 & 293 & 118 & & & 6.2376 & $3.371-11.685$ & 0.000 \\
\hline \multirow[t]{3}{*}{ T4 } & 27 & 4 & & & 2.309 & $0.694-7.676$ & 0.172 \\
\hline & LVI (n) & & & & & & \\
\hline & Negative & Positive & 34.053 & 0.000 & & & \\
\hline T1 & 46 & 5 & & & 1 & & \\
\hline $\mathrm{T} 2$ & 183 & 16 & & & 0.804 & $0.280-2.310$ & 0.686 \\
\hline T3 & 300 & 111 & & & 3.404 & $1.319-8.787$ & 0.011 \\
\hline \multirow[t]{3}{*}{ T4 } & 23 & 8 & & & 3.200 & $0.941-10.886$ & 0.063 \\
\hline & $\mathrm{TD}(\mathrm{n})$ & & 42.704 & 0.000 & & & \\
\hline & Negative & positive & & & & & \\
\hline $\mathrm{T} 1$ & 49 & 2 & & & 1 & & \\
\hline T2 & 195 & 4 & & & 0.503 & $0.089-2.824$ & 0.435 \\
\hline T3 & 329 & 82 & & & 6.106 & $1.455-25.631$ & 0.013 \\
\hline \multirow[t]{3}{*}{ T4 } & 24 & 7 & & & 7.146 & $1.378-37.044$ & 0.019 \\
\hline & \multicolumn{2}{|c|}{ Differentiation (n) } & 19.996 & 0.000 & & & \\
\hline & High grade & Low grade & & & & & \\
\hline T1 & 42 & 9 & & & 1 & & \\
\hline T2 & 143 & 56 & & & 1.828 & $0.835-4.000$ & 0.131 \\
\hline T3 & 248 & 163 & & & 3.067 & $1.454-6.471$ & 0.003 \\
\hline \multirow[t]{4}{*}{ T4 } & 14 & 17 & & & 5.667 & $2.065-15.547$ & 0.001 \\
\hline & $\operatorname{Sex}(n)$ & & 4.741 & 0.192 & & & \\
\hline & Male & Female & & & & & \\
\hline & & & $x^{2}$ & $\mathrm{P}$ & Exp & $95 \% \mathrm{Cl}$ & $\mathrm{P}$ \\
\hline
\end{tabular}




\begin{tabular}{|c|c|c|c|c|c|c|c|}
\hline & & & $x^{2}$ & $\mathbf{P}$ & Exp & $95 \% \mathrm{Cl}$ & $\mathbf{P}$ \\
\hline T1 & 26 & 25 & & & & & \\
\hline T2 & 128 & 71 & & & & & \\
\hline T3 & 273 & 138 & & & & & \\
\hline \multirow[t]{3}{*}{$\mathrm{T} 4$} & 20 & 11 & & & & & \\
\hline & \multicolumn{2}{|c|}{ Tumor location (n) } & 13.065 & 0.004 & & & \\
\hline & $\leq 5 \mathrm{~cm}$ & $>5 \mathrm{~cm}$ & & & & & \\
\hline T1 & 13 & 38 & & & 1.196 & $0.440-3.247$ & 0.726 \\
\hline T2 & 91 & 108 & & & 0.486 & $0.213-1.107$ & 0.486 \\
\hline T3 & 135 & 276 & & & 0.836 & $0.375-1.866$ & 0.836 \\
\hline $\mathrm{T} 4$ & 9 & 22 & & & 1 & & \\
\hline
\end{tabular}

Logistic regression analysis revealed relationships between $T$ stage and these significant pathologic factors. Regarding LVI, compared to T1 patients, a significantly higher proportion of T3 patients were positive for LVI $(\mathrm{OR}=3.404,95 \% \mathrm{Cl}: 1.319-8.787, \mathrm{P}=0.011)$; however, the same result was not observed in $\mathrm{T} 2$ patients $(\mathrm{P}=$ $0.686, \mathrm{OR}=0.804,95 \% \mathrm{Cl}: 0.280-2.310) . \mathrm{T} 4$ patients had a tendency towards a greater probability of positive $L V I$, but the difference was not significant $(P=0.063, O R=3.200,95 \%$ Cl: $0.941-10.886)$.

Regarding $\mathrm{PNI}$, compared to T2 patients, a significantly higher proportion of T3 patients had PNI (OR = $6.2376,95 \% \mathrm{Cl}: 3.371-11.685, \mathrm{P}=0.000)$; however, the same result was not observed in T4 patients $(\mathrm{OR}=$ $2.309,95 \% \mathrm{Cl}: 0.694-7.676, \mathrm{P}=0.172)$.

Regarding TD, compared to T1 patients, there was a significantly higher proportion of T3 and T4 but not T2 patients with TD $(O R=6.106,95 \% \mathrm{Cl}: 1.455-25.631, \mathrm{P}=0.013 ; \mathrm{OR}=7.146,95 \% \mathrm{Cl}: 1.378-37.044, \mathrm{P}=0.019$; $\mathrm{OR}=0.503,95 \% \mathrm{Cl}: 0.089-2.824, \mathrm{P}=0.435$, respectively).

Regarding tumour differentiation grade, compared to T1 patients, a significantly higher chance of T3 and T4 but not $\mathrm{T} 2$ patients had poorly differentiated disease $(\mathrm{OR}=3.067,95 \% \mathrm{Cl}: 1.454-6.471, \mathrm{P}=0.003 ; \mathrm{OR}=$ 5.667, 95\% Cl: $2.065-15.547, \mathrm{P}=0.001 ; \mathrm{OR}=1.828,95 \% \mathrm{Cl}: 0.835-4.000, \mathrm{P}=0.131$ ).

Regarding tumour location, there were no differences between patients with T4 disease and those with T1 $(P=0.726), T 2(P=0.486)$ and $\mathrm{T} 3(P=0.836)$ disease.

\section{Clinicopathologic variables that may be correlated with LNM}

We also analysed the clinicopathologic factors that could be correlated with pathologic lymph node metastasis (LNM), as shown in Table 4. Based on univariate analysis, patient age, sex, and tumour location did not significantly affect LNM. However, LVI, PNI, pathologic T stage, tumour differentiation grade, and TD (all $\mathrm{P}=0.000$ ) were significantly correlated with LNM. When these factors were entered into a multivariate 
analysis using a logistic regression model, $\mathrm{LVI}(\mathrm{OR}=3.882,95 \% \mathrm{Cl}=2.338-6.440, \mathrm{P}=0.000)$, pathological $\mathrm{T}$ stage $(\mathrm{OR}=1.969,95 \% \mathrm{Cl}=1.471-2.635, \mathrm{P}=0.00)$, tumour differentiation grade $(\mathrm{OR}=2.255,95 \% \mathrm{Cl}=$ 1.544-3.293, $\mathrm{P}=0.000)$, and TD $(\mathrm{OR}=27.645,95 \% \mathrm{Cl}=9.805-77.947, \mathrm{P}=0.000)$ retained significance as risk factors for $\mathrm{LNM}$. However, $\mathrm{PNI}(\mathrm{P}=0.452, \mathrm{OR}=1.213,95 \% \mathrm{Cl}=0.734-2.003)$ was not a risk factor for LNM based on the multivariate analysis. 
Table 4

Associations between clinicopathologic variables and lymph node metastasis (LNM)

\begin{tabular}{|c|c|c|c|c|c|c|c|}
\hline & $\begin{array}{l}\text { LNM } \\
\text { Negative } \\
(381)\end{array}$ & $\begin{array}{l}\text { LNM } \\
\text { positive } \\
(311)\end{array}$ & & $\begin{array}{l}\text { Univariate } \\
\text { analysis } \\
(\mathrm{P})\end{array}$ & Exp & $\begin{array}{l}\text { Adjusted } \\
\text { odds } \\
\text { ratio } \\
(95 \% \mathrm{Cl})\end{array}$ & $\begin{array}{l}\text { Multivariate } \\
\text { analysis (P) }\end{array}$ \\
\hline Sex & & & $X^{2}=0.886$ & 0.380 & & & \\
\hline Male & 252 & 195 & & & & & \\
\hline Female & 129 & 116 & & & & & \\
\hline Age & $\begin{array}{l}61.92 \pm \\
11.25 \\
(381)\end{array}$ & $\begin{array}{l}61.29 \pm \\
11.57 \\
(311)\end{array}$ & $F=0.078$ & 0.780 & & & \\
\hline $\begin{array}{l}\text { Tumor } \\
\text { location }\end{array}$ & & & $X^{2}=1.445$ & 0.229 & & & \\
\hline$\leq 5 \mathrm{~cm}$ & 129 & 119 & & & & & \\
\hline$>5 \mathrm{~cm}$ & 252 & 192 & & & & & \\
\hline PNI & & & $X^{2}=28.859$ & 0.000 & 1.213 & $\begin{array}{l}0.734- \\
2.003\end{array}$ & 0.452 \\
\hline Negative & 335 & 223 & & & & & \\
\hline Positive & 46 & 88 & & & & & \\
\hline LVI & & & $X^{2}=83.659$ & 0.000 & 3.882 & $\begin{array}{l}2.338- \\
6.440\end{array}$ & 0.000 \\
\hline Negative & 352 & 200 & & & & & \\
\hline Positive & 29 & 111 & & & & & \\
\hline $\begin{array}{l}\text { Pathological } \\
\text { T stage }\end{array}$ & & & $x^{2}=79.238$ & 0.000 & 1.969 & $\begin{array}{l}1.471- \\
2.635\end{array}$ & 0.000 \\
\hline T1 & 41 & 10 & & & 1 & & \\
\hline $\mathrm{T} 2$ & 152 & 47 & & & 1.309 & $\begin{array}{l}0.559- \\
3.065\end{array}$ & 0.535 \\
\hline T3 & 178 & 233 & & & 3.126 & $\begin{array}{l}1.380- \\
7.082\end{array}$ & 0.006 \\
\hline T4 & 10 & 21 & & & 4.730 & $\begin{array}{l}1.499- \\
14.927\end{array}$ & 0.008 \\
\hline Differentiation & & & $X^{2}=42.700$ & 0.000 & 2.255 & $\begin{array}{l}1.544- \\
3.293\end{array}$ & 0.000 \\
\hline High & 287 & 160 & & & & & \\
\hline
\end{tabular}




\begin{tabular}{|c|c|c|c|c|c|c|c|}
\hline & $\begin{array}{l}\text { LNM } \\
\text { Negative } \\
(381)\end{array}$ & $\begin{array}{l}\text { LNM } \\
\text { positive } \\
(311)\end{array}$ & & $\begin{array}{l}\text { Univariate } \\
\text { analysis } \\
\text { (P) }\end{array}$ & Exp & $\begin{array}{l}\text { Adjusted } \\
\text { odds } \\
\text { ratio } \\
(95 \% \mathrm{Cl})\end{array}$ & $\begin{array}{l}\text { Multivariate } \\
\text { analysis }(P)\end{array}$ \\
\hline Low & 94 & 151 & & & & & \\
\hline TD & & & $X^{2}=131.791$ & 0.000 & 27.645 & $\begin{array}{l}9.805- \\
77.947\end{array}$ & 0.000 \\
\hline Negative & 377 & 220 & & & & & \\
\hline Positive & 0 & 95 & & & & & \\
\hline
\end{tabular}

As shown in Table 2, Fig. 2 and Fig. 3, we further confirmed the correlation between the primary tumour (T) and nodule status $(\mathrm{N})$ by a binary logistic regression model. Compared with T1, the HRs of LNM for T2, T3, and T4 patients were 1.309 (95\% Cl: $0.559-3.065, \mathrm{P}=0.535), 3.126(95 \% \mathrm{Cl}: 1.380-7.082, \mathrm{P}=0.006)$ and 4.730 (95\% Cl: 1.499-14.927, $\mathrm{P}=0.008)$, respectively. More advanced T stages (T3 and T4) were significantly associated with a higher incidence of LNM.

\section{Discussion}

The results of the present study demonstrated the relationships among clinical and pathological factors in patients undergoing surgery for rectal cancer. These clinicopathological factors included sex, age, tumour location, differentiation grade, LVI, PNI, TD, and pathological T and N stages.

Our study demonstrated that the number of male rectal cancer patients was approximately 1.8 times that of female patients. However, no significant difference in age at onset was observed between female and male rectal cancer patients.

LVI is defined as the involvement of tumours in vascular and lymphatic structures [9-10]. In our study, 20.2\% of 692 patients had LVI, which was in agreement with previous studies that reported that the incidence of LVI in rectal cancer patients who underwent curative surgery was $20-30 \%$ based on pathological evaluation[11-14].

The regional $L N$ is the most common site of tumour metastasis. To accurately evaluate $L N M$, as many LNs as possible should be assessed to determine the $\mathrm{N}$ stage. Both the total number of regional $\mathrm{LNs}$ removed and the number of positive LNs involved should be reported. The AJCC 7th and 8th editions state that it is important to obtain and examine at least $12 \mathrm{LNs}[8]$. The prior 6 th edition suggested obtaining a range from 7 to 14 LNs. In this study, an average of $18.56 \pm 5.68$ (from 10-49) LNs were obtained and examined.

We determined that LVI, pathological T stage, differentiation grade, and TD were significantly related to $\mathrm{N}$ based on univariate and multivariate analyses. The presence of LVI and TD, poor differentiation and advanced T stage (T3 and T4) were significantly associated with LNM. PNI was also an independent risk factor for $\mathrm{N}$ in univariate analysis but not multivariate analysis. The HRs were calculated for every risk factor 
in our study and are shown in Table 4. The strongest risk factor was TD (hazard ratio $(\mathrm{HR})=27.645 ; 95 \% \mathrm{Cl}$ 9.805-77.947; $P=0.000)$, partly resulting from TD accounting for a small portion of the $\mathrm{N}$ stage. From the AJCC 7th (2010) edition to the 8th edition, the new nodal subclassification category N1c is used if there is TD but no concurrent positive LNs. In our study, 13.7\% (95/692) of patients had TDs, including $4.5 \%$ $(18 / 400)$ of patients who lacked positive LNs and $26.4 \%(77 / 292)$ of patients who had positive LNs. Similar to Chen's report[15] (approximately $10 \%$ of colorectal cancers have TDs, and $2.5 \%$ of colon cancer and $3.3 \%$ of rectal cancer have TDs without positive LNs). Our finding was slightly lower than the $14.8 \%$ in stage III colorectal cancer previously reported[16].

We also found that the higher the T stage was, the higher the probability of TD. Compared with T1 stage, stage T3 $(\mathrm{OR}=6.106,95 \% \mathrm{Cl}=1.455-25.631, \mathrm{P}=0.013)$ and T4 $(\mathrm{OR}=7.146,95 \% \mathrm{Cl}=1.378-37.044, \mathrm{P}=$ $0.019)$ were more likely to have positive TDs; the same result was not observed for stage $T 2(P=0.435, O R=$ $0.503,95 \% \mathrm{Cl}=0.089-2.824)$. Many studies have shown that the presence of TDs is associated with advanced tumour growth and reduced disease-free and overall survival[17-21].

Our study explored the relationships between pathological T and $\mathrm{N}$ stages in 692 patients receiving surgery and not neoadjuvant therapy. In our study, the overall LN involvement was $44.9 \%$. The percentage of LNI at each pathologic $\mathrm{T}$ stage was as follows: $19.6 \%$ in T1, 23.6\% in T2, 56.7\% in T3, and $67.8 \%$ in T4. A previous study showed that the percentage of LNI at each tumour depth was as follows: $5.7 \%$ for T1; 19.6\% for T2; $65.7 \%$ for T3; 78.8\% for T4[22]. Another study reported that the overall incidence of LNM was $12.7 \%$ for colorectal cancer (5.6\% for T1 and 14.5\% for T2; $p=0.021$ )[23]. In Patel's study[24], no patients with stage T1/2 N0 rectal adenocarcinoma who underwent resection without neoadjuvant or adjuvant CRT had LNM. The lower rate of LNM in patients with T1 disease in these previous studies could be due to positive TDs not being categorized as N1c before the AJCC 7th edition or selection bias. Compared to stage T1, there is a slight increase in the LNM rate in T2, although it is not significant; however, there is are significant increases in T3 and T4 compared with T1 (Table 2, Fig. 2 and Fig. 3). This conclusion was confirmed by univariate and multivariate analyses (Table 4). Compared with T1, the hazard ratios of LNM for T3 and T4 were 3.126 (95\% Cl: $1.380-7.082, \mathrm{P}=0.006)$ and 4.730 (95\% Cl: 1.499-14.927, $\mathrm{P}=0.008)$, respectively, but a significantly increased risk was not observed for $\mathrm{T} 2$ patients $(\mathrm{HR}=1.309,95 \% \mathrm{Cl}: 0.559-3.065, \mathrm{P}=0.535)$. Therefore, increased depths of tumour penetration are associated with a greater incidence of LNM.

\section{Conclusion}

The present study indicated that the presence of LVI, PNI, TD, low pathological differentiation grade, and advanced pathological T stage (T3 and T4) were independent factors associated with a higher incidence of LNM on univariate and multivariate analyses.

\section{Abbreviations}

PNI

perineural invasion

LVI

Page $13 / 19$ 
lymphovascular invasion

TD

tumour deposit

LNM

lymph node metastasis

$\mathrm{nRCT}$

neoadjuvant radiochemotherapy

TME

total mesorectal excision

LARC

locally advanced rectal carcinoma

LNs

lymph nodes

HR

The hazard rati

$\mathrm{Cl}$

confidence interval

LNM

lymph node metastasis

\section{Declarations}

\section{Ethical Approval and Consent to participate}

This retrospective study was approved by the Institutional Research Ethics Committee of the First Affiliated Hospital of Nanjing Medical University (No:2019-SR-316).

\section{Consent for publication}

All authors of this paper have read and and complied with author guidelines. The contents of this manuscript have not been copyrighted or published previously. The contents of this manuscript are not under consideration for publication elsewhere. The contents of this manuscript will not be copyrighted, submitted, or published elsewhere while acceptance by the manuscript is under consideration. All authors approve to publish this article in Journal of Experimental \& Clinical Cancer Research.

\section{Availability of supporting data}

Not applicable

\section{Competing interests}

The authors have declared that no competing interests exist.

\section{Funding}


None

\section{Authors' contributions}

Liping Xu, Chi Zhang and Zhaoyue Zhang contributed equally to this work as first authors.

Liping Xu, Chi Zhang, Zhaoyue Zhang and Xinyu Tang carried out the data collection, data analysis and drafted the manuscript; Xinchen Sun and Qin Qin supervised the research program and edited the manuscript; Xinchen Sun and Qin Qin had significant roles in the study design and manuscript review. All authors read and approved the final manuscript.

\section{Acknowledgements}

Not applicable

\section{References}

1. Heald R J, Husband E M, Ryall R D H. The mesorectum in rectal cancer surgery-the clue to pelvic recurrence?[J]. British Journal of Surgery, 1982, 69(10): 613-616.

2. Kapiteijn E, Marijnen C A M, Nagtegaal I D, et al. Preoperative radiotherapy combined with total mesorectal excision for resectable rectal cancer[J]. New England Journal of Medicine, 2001, 345(9): 638-646.

3. Bosset J F, Collette L, Calais G, et al. EORTC Radiotherapy Group Trial 22921[J]. Chemotherapy with preoperative radiotherapy in rectal cancer. N Engl J Med, 2006, 355(11): 1114-1123.

4. Gérard J P, Conroy T, Bonnetain F, et al. Preoperative radiotherapy with or without concurrent fluorouracil and leucovorin in T3-4 rectal cancers: results of FFCD 9203[J]. Journal of clinical oncology, 2006, 24(28): 4620-4625.

5. Kapiteijn E, Marijnen CA, Nagtegaal ID, Putter H, Steup WH, Wiggers T, et al. Preoperative radiotherapy combined with total mesorectal excision for resectable rectal cancer. N Engl J Med. 2001;345(9):638-46.

6. van Gijn W, Marijnen C A M, Nagtegaal I D, et al. Preoperative radiotherapy combined with total mesorectal excision for resectable rectal cancer: 12-year follow-up of the multicentre, randomised controlled TME trial[J]. The lancet oncology, 2011, 12(6): 575-582.

7. Bosset J F, Calais G, Mineur L, et al. Fluorouracil-based adjuvant chemotherapy after preoperative chemoradiotherapy in rectal cancer: long-term results of the EORTC 22921 randomised study[J]. The lancet oncology, 2014, 15(2): 184-190.

8. Breugom A J, Swets M, Bosset J F, et al. Adjuvant chemotherapy after preoperative (chemo) radiotherapy and surgery for patients with rectal cancer: a systematic review and meta-analysis of individual patient data[J]. The lancet oncology, 2015, 16(2): 200-207.

9. Jin M , Frankel W L . Lymph Node Metastasis in Colorectal Cancer. Surg Oncol Clin N Am.2018. 27. 401412.

10. Hoda S A, Hoda R S, Merlin S, et al. Issues relating to lymphovascular invasion in breast carcinoma[J]. Advances in anatomic pathology, 2006, 13(6): 308-315. 
11. Walgenbach-Bruenagel $G$, Tolba $R H$, Varnai $A D$, et al. Detection of lymphatic invasion in early stage primary colorectal cancer with the monoclonal antibody D2-40[J]. European surgical research, 2006, 38(5): 438-444.

12. Law W L, Chu K W. Local recurrence following total mesorectal excision with double-stapling anastomosis for rectal cancers: analysis of risk factors[J]. World journal of surgery, 2002, 26(10): 1272.

13. Ptok H, Meyer F, Steinert R, et al. No prognostic impact of isolated lymphovascular invasion after radical resection of rectal cancer-results of a multicenter observational study[J]. International journal of colorectal disease, 2007, 22(7): 749-756.

14. Dresen $\mathrm{R} C$, Peters E E M, Rutten $\mathrm{H} J \mathrm{~T}$, et al. Local recurrence in rectal cancer can be predicted by histopathological factors[J]. European Journal of Surgical Oncology (EJSO), 2009, 35(10): 1071-1077.

15. Lee J H, Jang H S, Kim J G, et al. Lymphovascular invasion is a significant prognosticator in rectal cancer patients who receive preoperative chemoradiotherapy followed by total mesorectal excision[J]. Annals of surgical oncology, 2012, 19(4): 1213-1221.

16. Chen V W, Hsieh M C, Charlton M E, et al. Analysis of stage and clinical/prognostic factors for colon and rectal cancer from SEER registries: AJCC and collaborative stage data collection system[J]. Cancer, 2014, 120: 3793-3806.

17. Lo DS, Pollett A, Siu LL, Gallinger S, Burkes RL. Prognostic significance of mesenteric tumor nodules in patients with stage III colorectal cancer. Cancer. 2008;112(1):50-4.

18. Nagtegaal I D, Quirke P. Colorectal tumour deposits in the mesorectum and pericolon; a critical review[J]. Histopathology, 2007, 51(2): 141-149.

19. Puppa G, Ueno H, Kayahara M, et al. Tumor deposits are encountered in advanced colorectal cancer and other adenocarcinomas: an expanded classification with implications for colorectal cancer staging system including a unifying concept of in-transit metastases[J]. Modern pathology, 2009, 22(3): 410415.

20. Tong L, Gao P, Wang Z, et al. Is the seventh edition of the UICC/AJCC TNM staging system reasonable for patients with tumor deposits in colorectal cancer?[J]. Annals of surgery, 2012, 255(2): 208-213.

21. Ueno $\mathrm{H}$, Hashiguchi $\mathrm{Y}$, Shimazaki $\mathrm{H}$, et al. Peritumoral deposits as an adverse prognostic indicator of colorectal cancer[J]. The American Journal of Surgery, 2014, 207(1): 70-77.

22. Ueno $H$, Mochizuki $H$, Hashiguchi $Y$, et al. Extramural cancer deposits without nodal structure in colorectal cancer: optimal categorization for prognostic staging[J]. American journal of clinical pathology, 2007, 127(2): 287-294.

23. Sitzler $\mathrm{P}$ J, Seow-Choen $\mathrm{F}$, Ho Y H, et al. Lymph node involvement and tumor depth in rectal cancers[J]. Diseases of the colon \& rectum, 1997, 40(12): 1472-1476.

24. Chok K S H , Law W L . Prognostic Factors Affecting Survival and Recurrence of Patients with pT1 and pT2 Colorectal Cancer[J]. World Journal of Surgery, 2007, 31(7):1485-1490.

25. Patel S A, Chen Y H, Hornick J L, et al. Early- Stage Rectal Cancer: Clinical and Pathologic Prognostic Markers of Time to Local Recurrence and Overall Survival After Resection[J]. Diseases of the Colon \& Rectum, 2014, 57(4):449-459. 
Figures

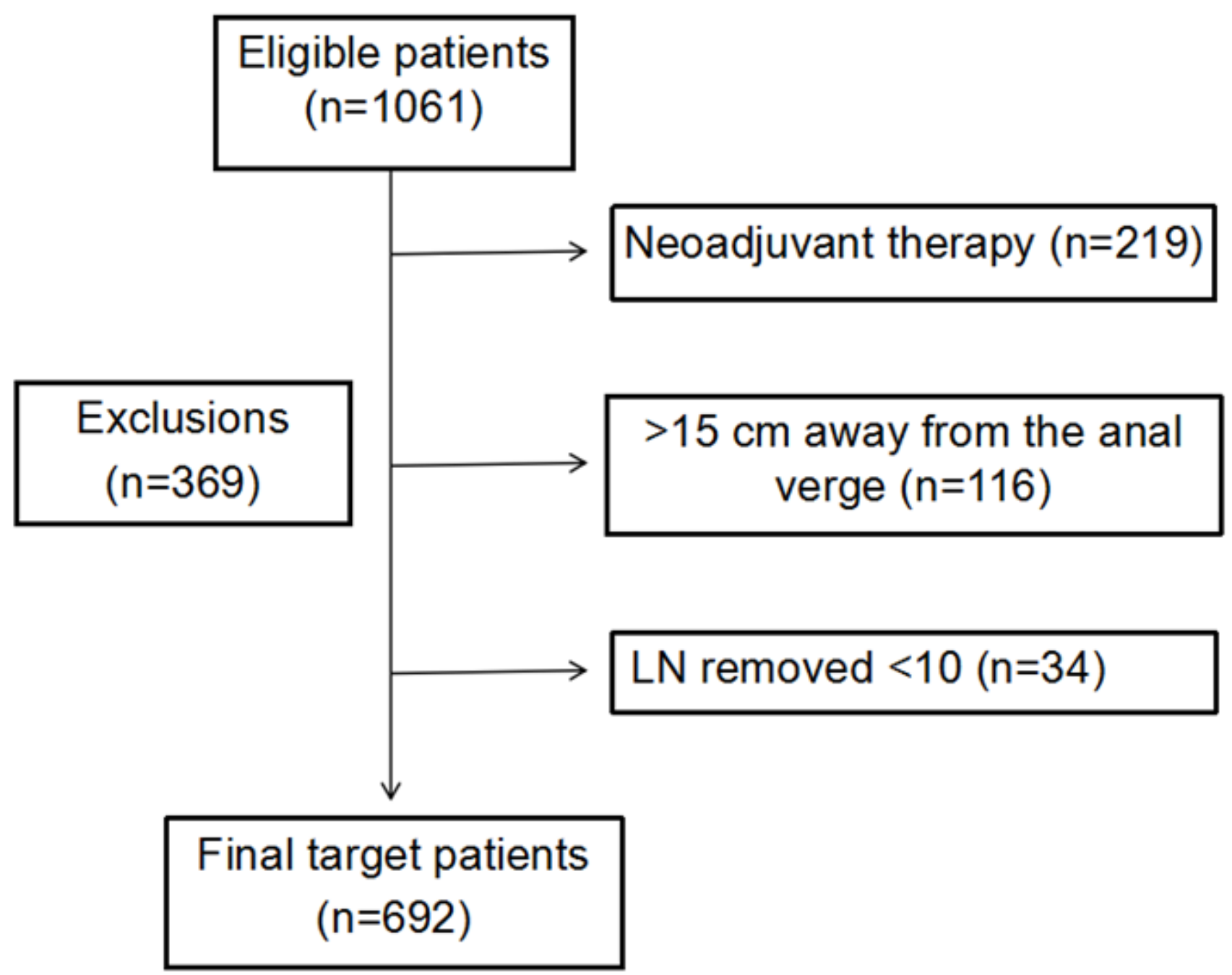

Figure 1

Flow chart for screening eligible patients. 


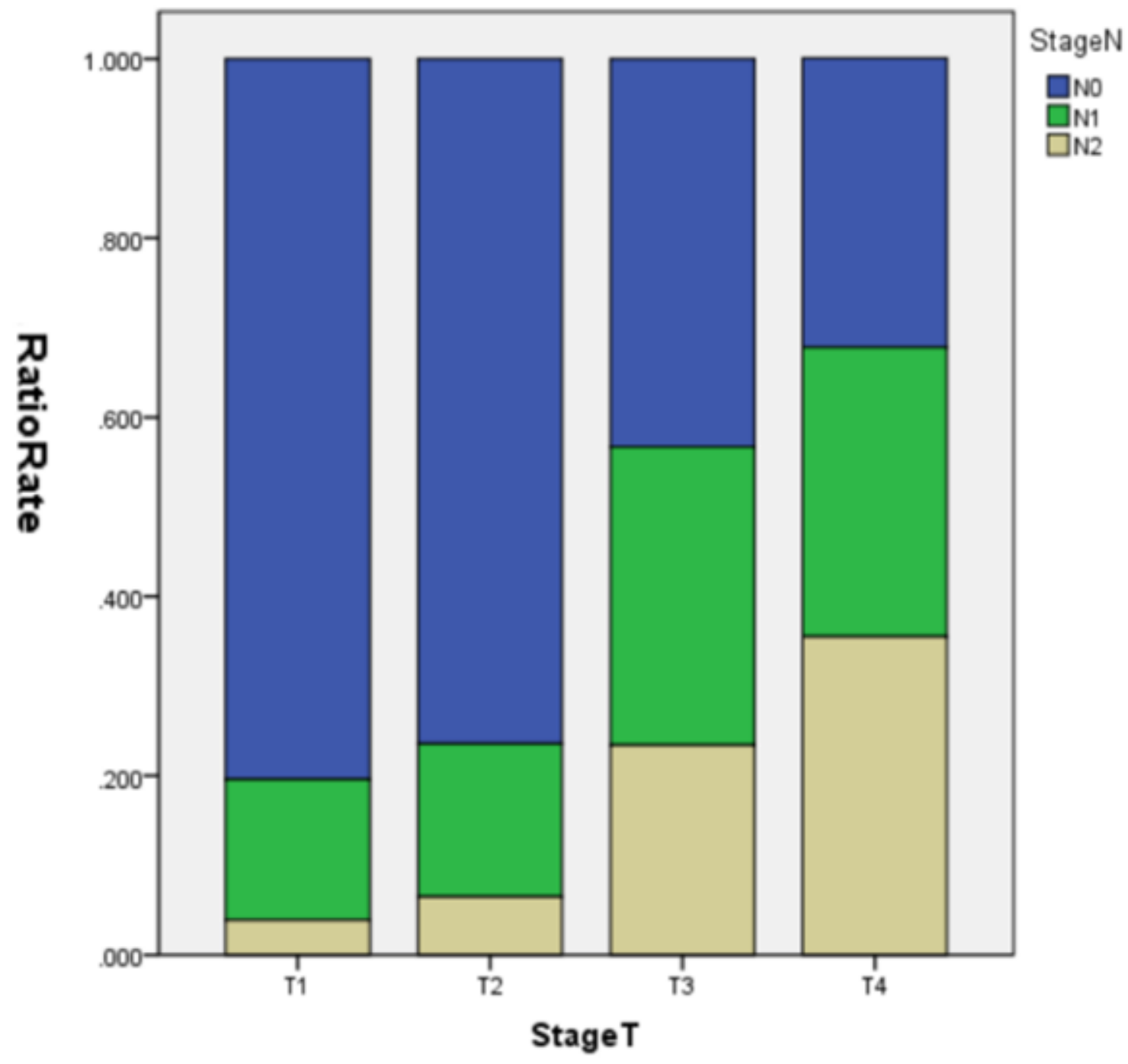

Figure 2

Stacked bar chart of N0-2 ratio for each T stage in 692 patients with rectal cancer. G=0.579, $\mathrm{P}=0.000$ 


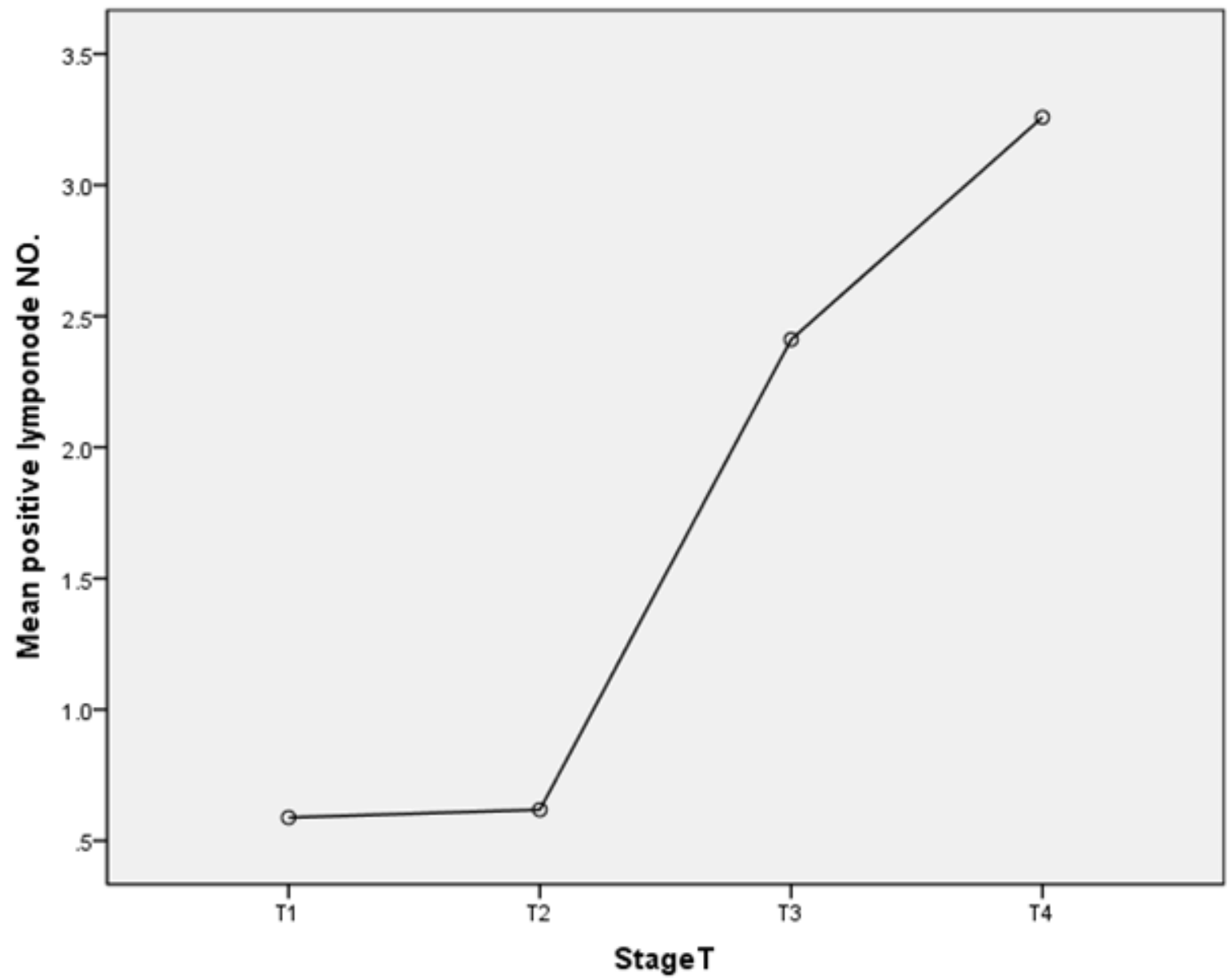

Figure 3

The mean number of positive lymph nodes for each T stage. 